\title{
Biodiversity of molecular profile of Staphylococcus aureus isolated from bovine mastitis cases in West Algeria
}

\author{
Nadjia BENHAMED* and Mebrouk Kihal \\ Laboratory of Applied Microbiology, Department of Biology, Faculty of Science, Oran University, BP16, Es-senia 31000 \\ Oran, Algeria.
}

Accepted 3 April, 2013

\begin{abstract}
Bovine mastitis is an inflammation of the mammary gland with local and or symptoms that occasionally result in a systemic infection. This disease has a profound impact on animal welfare and milk quality, and the most costly disease affecting dairy cows. The bacteria Staphylococcus aureus is one of the most frequently isolated pathogens from both subclinical and clinical infections. This study was conducted to investigate the phenotypic and genotypic characterization of $S$. aureus involved in dairy cow mastitis in West Algeria. A total of 141 isolates of $S$. aureus isolated from quarter milk samples were collected from dairy cows. All retained $S$. aureus species contained gyr gene and were identified by molecular typing. The presence of resistance was evaluated in $S$. aureus. Staphylococci antimicrobial resistance was performed by detection of $m e c A$ gene. Several virulence factors including toxin of the Pantin Valentine leukocidin coding gene ( $p v l)$ were also investigated by polymerase chain reaction (PCR). Only one strain of $S$. aureus was mecA - and pvl+ gene.
\end{abstract}

Key words: Mastitis, S. aureus, Gyr A, PCR, mecA, pvl.

\section{INTRODUCTION}

Mastitis, the most expensive disease of dairy cows, continues to be a persistent problem in the dairy industry (Barkema et al., 2009; Le Marechal et al., 2011). Mastitis, inflammation of the mammary gland with local and or general symptoms that occasionally result in a systemic infection, can be caused by a wide range of microorganisms, including gram-negative and gram-positive bacteria (Le Marechal et al., 2011).

Staphylococcus aureus is one of the most frequently isolated pathogens from both sub-clinical and chronic infections (Watts 1988). S. aureus still remains one of the most significant organisms associated with clinical and subclinical bovine mastitis, not only in Algeria but worldwide. This disease is considered to be the most frequent and most costly production disease in dairy herds of de- veloped countries (Fourichon et al., 2001). Mastitis is one of the dominant pathological dairy farming actually decreased milk production per cow due to the prevalence of clinical and subclinical mastitis (Le Marechal et al., 2011). The main etiology is infectious. It results in the majority of cases by cell type inflammatory response involving an increase in the cell concentration in milk, cell counts in the diagnosis of mastitis is essential and the results should be according to the results of the CMT (California Mastitis test).

Bovine mastitis produces a wide variety of problems in the dairy farm. The treatment of this disease is based on the use of antibiotics which are not always effective.

These drugs are also responsible for the presence of residues the milk the increase antibiotic-resistant strains. 
Probiotic products were proposed as a valid alternative to antibiotic therapies and are also useful for the prevention of infectious syndromes (Espeche et al., 2012). S. aureus is the most predominant contagious pathogen responseble for clinical and subclinical infections in lactating cows (Kerro-Dego et al., 2002).

This study was conducted to investigate the phenotypic and genotypic characterization of $S$. aureus involved in dairy cow mastitis in West Algeria. The presence of resistance was evaluated in $S$. aureus. Staphylococci antimicrobial resistance was performed by detection of mecA gene and several virulence factors including toxin of the Pantin Valentine leukocidin coding gene ( $p v /$ ) by polymerrase chain reaction (PCR).

\section{MATERIALS AND METHODS}

\section{Bacteriological analysis}

Milk samples were analyzed in Applied Microbiology Laboratory, Faculty of Sciences, Oran University. Milk samples were cultured on several media, on blood (5\% sheep blood) agar plates, incubited at $37^{\circ} \mathrm{C}$ for $24 \mathrm{~h}$. Growth on the plates was confirmed by additional laboratory tests in accordance. $S$. aureus was identified by means of typical colony and cells morphology, catalase reaction, by coagulase reaction using rabbit plasma (Quinn et al., 1994) (coagulase positive), or Pastorex (agglutination test) (Bio-rad, France) and biochemical characterization using the Api-staph system (Biomerieu, France). Strains expressed phenotypic resistance to cefoxitin confirmed by polymerase chain reaction detection of the mecA gene, typing of the accessory gene regulator (agr) and detection of control specific gene Gyr of $S$. aureus. Coagulase-negative staphylococci were identified by typical colony and cell morphology and coagulase reaction.

\section{Susceptibility testing}

Susceptibility testing was performed by disk (Bio-rad, France) diffusion method on Muller-Hinton agar plates. Testing was performed according to recommendation of Ca-SFM-veterinarian 2012 (Committee on Antimicrobial Company Information French Microbiology). The antibiotics tested were penicillin G (PG-6 $\mu \mathrm{g})$, kanamyin (K-30 $\mathrm{IU})$, gentamicin $(\mathrm{Gm}-15 \mu \mathrm{g})$, tetracyclin (Te-30UI), erythromycin (E15Ul), lincomycin (L-15 $\mu \mathrm{g})$, pristinamycin (PT-15 $\mu \mathrm{g}$ ), chloramphenicol $(\mathrm{C}-30 \mu \mathrm{g})$, pefloxacin (Pef-5 $\mu \mathrm{g}$ ), fosfomycin (Fos-5 $\mu \mathrm{g}$ ), cefoxitin (Fox-30 $\mu \mathrm{g}$ ), fusidic acid (FA-10 $\mu \mathrm{g}$ ), vancomycin (VA-30 $\mu \mathrm{g}$ ), oxacillin (Ox $5 \mathrm{cmg}$ ), Amikacin (10 mcg), carbenicillin (cB 100 $\mu \mathrm{g})$ and ciprofloxacin $(5 \mathrm{mcg})$. For testing susceptibility in staphylococci, $2 \% \mathrm{NaCl}$ was added to the broth and to Muller-Hinton agar plates. Control strains, S. aureus ATCC 43300 and S. aureus ATCC 25923 were tested in parallel with each batch of isolates (Smyth et al., 2001). The susceptibility to the cefoxitin of $S$. aureus was confirmed by polymerase chain reaction of the $m e c A$ gene (Elazhari et al., 2010).

\section{Bacterial DNA extraction}

DNA of each strain of $S$. aureus was extracted according to the standard protocol (Sambrook et al., 1989). The collected DNA was precipitated, described by electrophoresis on agarose gel and then stored at $-20^{\circ} \mathrm{C}$.

\section{Detection of mecA gene, GyrA gene and $p v l$ gene by PCR}

The confirmation of $S$. aureus species was performed on the basis of standard biochemical tests. The isolates were further characterized by molecular analysis amplifying the gene gyr typing of the accessory gene regulator (Brakstad et al., 1992). A duplex PCR for the simultaneous fragment 533 base pairs (bp) specific mecA gene and another $280 \mathrm{bp}$ fragment of the gene GyrA were used to prove the $S$. aureus species. The pathogenicity and virulence of $S$. aureus is associated with the capacity of this organism to produce several virulence factors including Panton-Valentine leukocidin (PVL) (Shittu et al., 2011). In addition, the Pantin-Valentine Leukocidin coding $\mathrm{pvl}$ gene was detected by simple PCR using specific fragment 433 pb (Sung et al., 2008); the primer used for mecA.

\section{Typing of agr gene (accessory gene regulator)}

Using PCR multiplex for search simultaneous fragment agr type (agr1; 440, agr2; 550, agr3; 300, agr4; 650), the research has been carried out for strains of $S$. aureus; the fragment used to define the type of agr $S$. aureus isolates. All amplification products were separated by electrophoresis on agarose gel $1.5 \%$ stained with ethidium bromide $(0.5 \mu \mathrm{g} / \mathrm{ml})$ in Tris-borate-EDTA TBE (at a rate of one to two drops added). Photographs of gels were taken under ultraviolet (UV) device (Gel Doc) (Sambrook et al., 1989).

\section{RESULTS}

Precise identification of $S$. aureus infected cows is important for successful implementation of a mastitis control program. Therefore, according to the phenotypic, biochemical properties as well as by amplification of the gyr gene, all of the isolates obtained in this study were identified as S. aureus. Data descriptive of Staphylococci strains isolated from quarter milk samples from clinical or subclinical mastitis cases in the study is shown in Table 1.

Detection of $p v l-l u k$ toxin by amplification of the $p v l$ gene from extracted DNA of the $S$. aureus strains reveled that positive amplification of the $533 \mathrm{pb}$ fragment of $\mathrm{pvl}$ gene from the extracted DNA of only one strains from 11, this strain had the following molecular profile agr3, mecA, $p v /+$, the rest of strains had a similar molecular profile (Figure 3).

\section{Antimicrobial susceptibility}

Antimicrobial susceptibility testing reported a high susceptibility of $S$. aureus strains to antimicrobial agents which was confirmed by PCR by the absence of mecA gene. Our results shows absence of $m e c A$ gene for all $S$. aureus strains which were phenotypically susceptible to cefoxitin and oxacillin.

Results presented in Figure 2 shows the absence of the mecA gene from extracted DNA of $S$. aureus strains tested; this result confirmed the antibiogram results for susceptibility to methicillin.

\section{DISCUSSION}

$S$. aureus is still considered one of the most common 
Table 1. Data descriptive of Staphylococci strains isolated from quarter milk samples from clinical or subclinical mastitis cases in the study.

\begin{tabular}{lcccccc}
\hline \multirow{2}{*}{$\begin{array}{l}\text { Staphylococci } \\
\text { strain }\end{array}$} & Clinical case \% & subclinical case $\%$ & Winter \% & Spring \% & Summer \% & Autumn \% \\
\hline S. aureus & 58.86 & 41.14 & 26 & 17.78 & 40 & 16.22 \\
SCN & 0 & 100 & 2.33 & 40 & 47.67 & 10 \\
\hline
\end{tabular}

SCN, Staphylococcus coagulase negative.

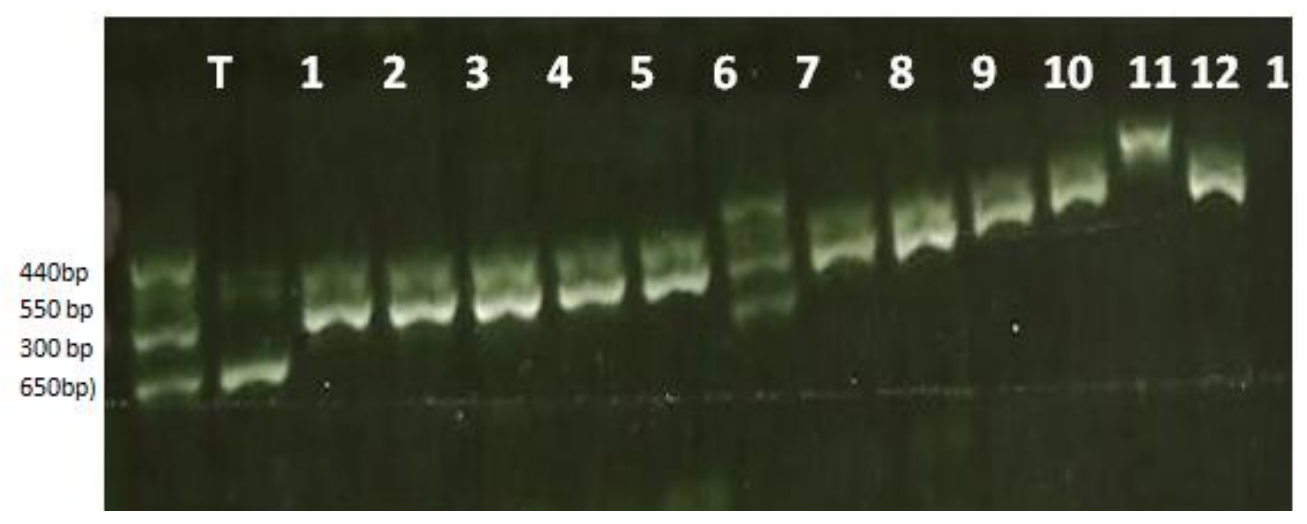

Figure 1. Agarose gel electrophoresis of polymerase chain reaction (PCR) amplification of agr $1 / 2 / 3 / 4$ gene.

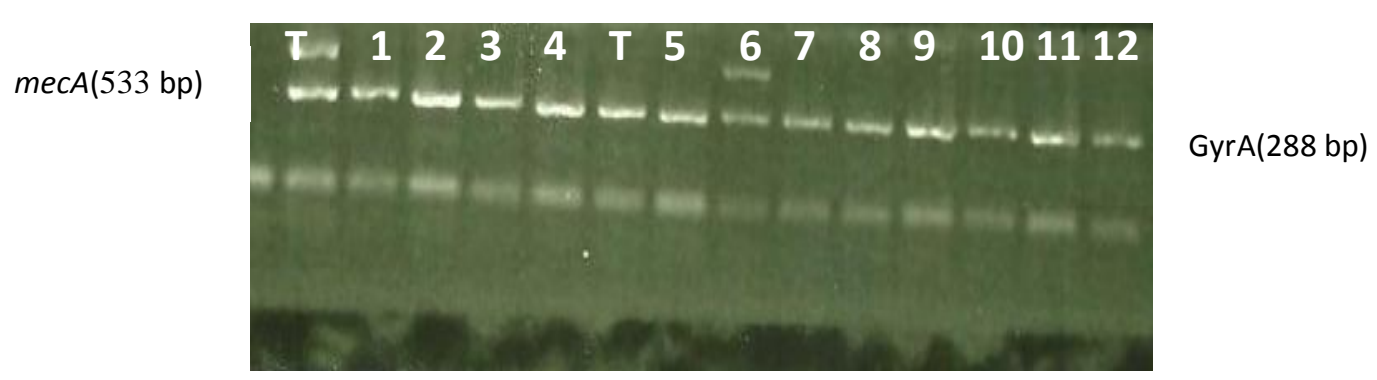

Figure 2. Agarose gel electrophoresis of polymerase chain reaction (PCR) double amplification of $m e c A$ and gyr A gene.

etiological agents associated with clinical and subclinical infections in lactating cows by Esmat and Bader (1996) and El-Seedy et al., 2010.

Precise identification of $S$. aureus-infected cows is important for successful implementation of a mastitis control program. Therefore, according to the phenotypic, biochemical properties as well as by amplification of the gyr gene (Figure 1), all of the isolates obtained in this study were identified as $S$. aureus (Dastmalchi, 2012).

Results presented in Figure 2 show the absence of the mecA gene from extracted DNA of $S$. aureus strains tested, this result confirmed the antimicrobial susceptibility testing results for susceptibility to methicillin. The strains of Staphylococcus aureus are (SASM) and showed high level of resistantance to eryhtromycine, ciprofloxacin, penicillin and a susceptibility to kanamycin. All strains showed also a high resistantance to to tetracycline, gentamicin and bacitracin (Figure 4).

Detection of $p v l-l u k$ toxin by amplification of the $p v l$ gene from extracted DNA of the $S$. aureus strains reveled that positive amplification of the $533 \mathrm{pb}$ fragment of $\mathrm{pvl}$ gene from the extracted DNA of only one strain from 11, this strain had the following profiles agr3, mecA-, pvl+ (Figure 3). This finding was comparable to the study of Sung et al. (2008). One isolate was positive for gene encoding the components of the Pantin-ValentineLeukocidin ( $p v /-l u k)$; these results are similar to those obtained by Monecke et al. (2011) and Shittu et al.(2011).

\section{Conclusions}

Our results indicate that several bacteria species of $S$. 


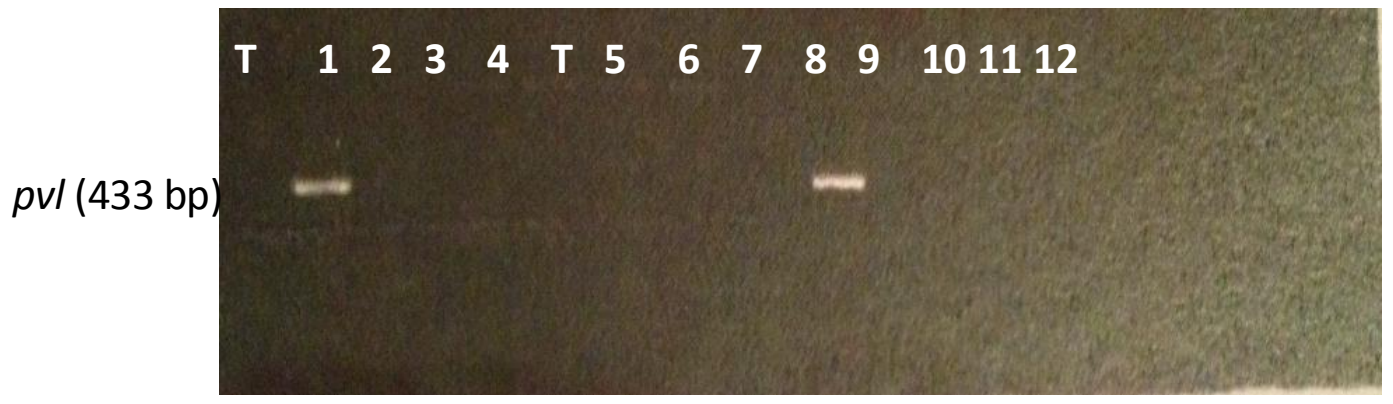

Figure 3. Agarose gel electrophoresis of polymerase chain reaction (PCR) double amplification of $P V L$ gene.

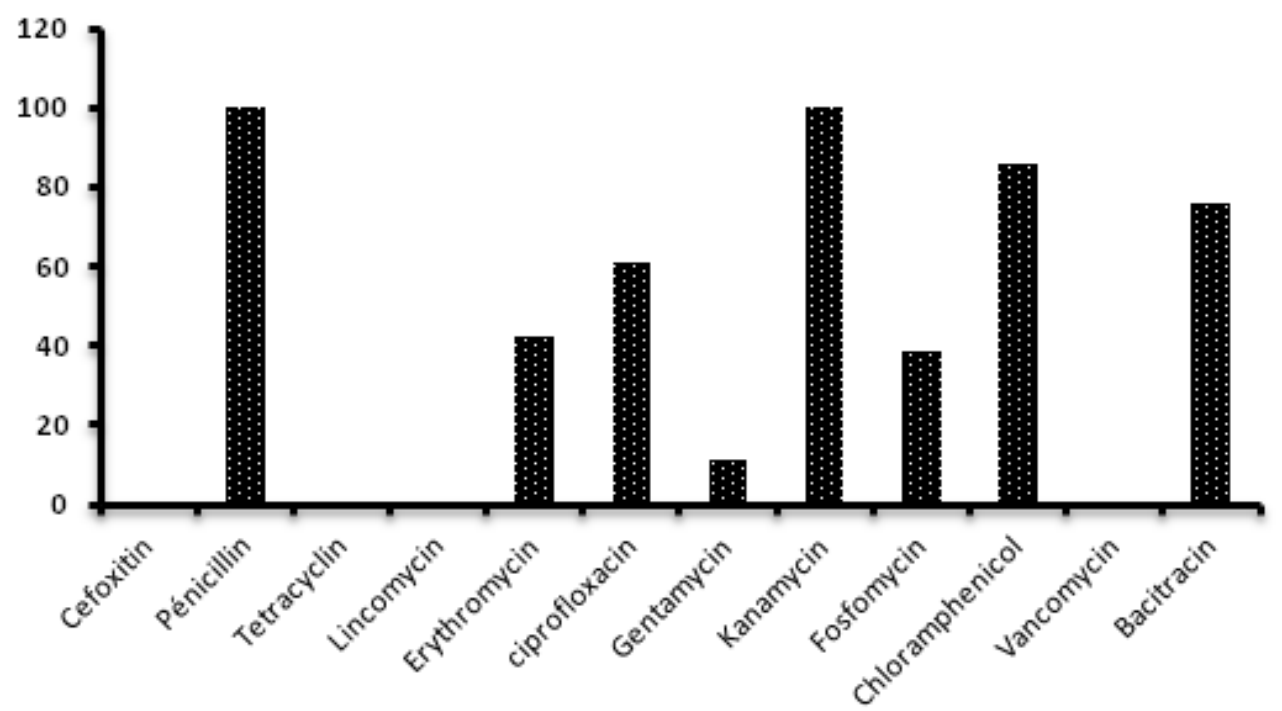

Figure 4. Antibiosusceptibility of strains of Staphylococcus aureus isolated.

aureus were found in mastitis cases. Genotypic and phenotypic identification of Staphylococcus aureus was confirmed by detection of gene gyrA and agr molecular typing. The antimicrobial susceptibility testing showed that $S$. aureus isolates from Oran Region West Algeria exhibited high susceptibility to all antimicrobial agents tested and due to the absence of mecA gene in all strains of $S$. aureus tested. The results of study show also that one strain of Staphylococcus aureus carried PVL-Luk toxin due to presence of $P V L$ gene which showed a susceptibility to cefoxitin.

\section{REFERENCES}

Barkema HW, Green MJ, Bradley AJ, Zadoks RN (2009). Invited review:The Role of contagiousDisease In Udder. health. J. Dairy. Sci. 92:4717-4729.

Brakstad OG, Aasbakk K, Maeland JA (1992). Detection of Staphylococcus aureus by polymerase chain reaction amplification of the nuc gene. J. Clin. Microbiol. 30:1654-1660.

Dastmalchi HS (2012). Coa types and antimicrobial resistance profile of Staphylococcus aureus isolates from cases of bovine mastitis. Comp. Clin. Pathol. 21:301-307.
Elazhari M, Zerouali K, Elhzbchi D, Cohen N, Elmalki A, Dersi N, Hassar M, Timinouni M, Saile R (2010). Sensibilité aux antibiotiques des souches de Staphylococcus aureus communautaires à Casablanca (Maroc). Revue Tunisienne d'Infection. 4:134-140.

El-Seedy FR, El-Shabrawy M, Hakim AS, Dorgham SM, Nagwa S, Bakry MA, Osman NMN (2010).Recent Techniques used for isolation and characterization of Staphylococcus aureus from Mastitis Cows. J. Am. Sci. 6:(2).

Esmat M , Bader A (1996).Some studies on mastitis meteritis agalcti syndrome in cows. Vet. Med. J. Giza. 44(2):303-309.

Espeche MC, Pellegrino M , Frola I, Larriestra A, Bogni C, Macías F (2012). Lactic acid bacteria from raw milk as potentially beneficial strains to prevent bovine mastitis. Mol. Boil. Genet. Biotechnol. 18:103-109.

Fourichon C, Seegers H, Beaudeau F, Bareille N (2001). Economic losses consecutive to health disorders in dairy farms in pays de la loire (france),52nd Meeting of the European Association of Animal Production, Budapest (H). pp. 26-29.

Kerro-Dego O, van Dijk JE, Nederbragt H (2002). Factors involved in the early pathogenesis of bovine Staphylococcus aureus mastitis with emphasis on bacterial adhesion and invasion. A review. Vet. Quart. 24:181-198.

Le Marechal C, thiery R, Le loir Y(2011). Mastitis impact on technologie proprerties of milk and quality of milk products- review. Dairy Sci. Technol. 91:247-282. 
Monecke S, Ehricht R, Slickers P, Wernery R, Johson B, Wernery $U$ (2011). Microarray-based genotyping of $S$. aureus isplates from camels. Vet. Microbiol. 150:309-314.

Quinn PJ, Carter ME, Maeker BK, Carter GR (1994). Clinical Veterinary Microbiology. Mosby, London, p.648.

Sambrook J,Fritsch EF, Manitatis T(1989). Molecular Cloning: A Laboratory Manual. 2nd ed. Cold Spring Harbor Laboratory Press, Cold Spring.

Shittu AO, Okon K, Adesida S, Oyedara O, Witte W, Strommenger $B$, Layer F, Nübel U (2011). Antibiotic resistance and molecular epidemiology of Staphylococcus aureus in Nigeria. BMC Microbiol. 11:92
Smyth RW, Kahlmeter G, Olsson B, Liljequist B, Hoffman B (2001).Methods for identifying methicillin resistancein Staphylococcus aureus. J. Hosp. Infect. 48(2):103-107.

Sung JML, Lloyd DH, Lindsay JA (2008). Staphylococcus aureus host specificity: comparative genomics of human versus animal isolates by multi-strain microarray. Microbiology 154:1949-1959.

Watts JL (1988). Etiological agents of bovine mastitis. Vet. Microbiol. 16:41-66, PMID: 3354192. 